\title{
Contractile Activity and Prostacyclin Generation in Isolated Coronary Arteries from Diabetic Dogs
}

\section{Dear Sir,}

Sterin-Borda et al. [1] have demonstrated that prostacyclin $\left(\mathrm{PGI}_{2}\right)$ increased the tension in coronary arteries obtained from pancreatectomised diabetic dogs whereas it caused relaxation in arteries from nondiabetic animals. This altered response to $\mathrm{PGI}_{2}$ in vessels from diabetic animals was associated with enhanced $\mathbf{P G I}_{2}$ production.

These findings are of considerable interest, but should be interpreted with caution since: (1) normal, rather than sham operated, animals were used for comparison. We have previously shown [2] that surgery alone (laparotomy only; laparotomy + dissection around blood vessels) in rats, results in a significant elevation of blood vessel $\mathrm{PGI}_{2}$ production; (2) total pancreatectomy removes more than insulin production alone; (3) no data regarding $\mathrm{PGI}_{2}$ production by vessels obtained from insulin-treated pancreatectomised dogs were presented.

Nevertheless, altered vascular responses by diabetic vessels are in accord with our observations of diabetic patients $[3,4]$. We found that $60 \%$ of diabetic patients studied did not respond to a carbon dioxide challenge with the increase in cerebral blood flow observed in normal subjects. In about $30 \%$ of the diabetic patients, carbon dioxide actually induced a fall in cerebral blood flow. Similar abnormalities in cutaneous vascular reactivity have been reported in diabetic children [5]. We have therefore suggested that abnormal vascular reactivity is a complication of diabetes, distinct from classical micro- or macrovascular disease [6]. The presence of abnormal vascular reactivity in diabetes has been shown to be unrelated to age, duration, time of onset or presence of other vascular complications of diabetes [7]. The mechanism underlying this abnormal vascular reactivity could involve an altered response of vascular smooth muscle to $\mathrm{PGI}_{2}$.

Sterin-Borda et al. [1] attributed the enhanced $\mathrm{PGI}_{2}$ synthesis in vessels from diabetic dogs to increased substrate availability following post-pancreatectomy lipolysis. However, we have shown that elevated non-esterified fatty acid concentrations, which are likely to occur in uncontrolled diabetic patients, result in a marked inhibition of $\mathrm{PGI}_{2}$ production by rat aortic rings [8]. Similarly, the addition of progressively higher concentrations of non-esterified fatty acids to plasma and human serum albumin (the plasma protein to which $\mathrm{PGI}_{2}$ probably binds and is thus stabilised), results in an acceleration of the rate of decay of $\mathrm{PGI}_{2}[9,10]$. Lipolysis may thus inhibit $\mathrm{PGI}_{2}$ production and accelerate $\mathbf{P G I}_{2}$ decay. The effect of enhanced lipolysis is thus likely to be complex as far as the synthesis, decay and bioavailability of $\mathrm{PGI}_{2}$ are concerned.

In the present paper [1], the authors do not consider their previous finding [11] that inhibitors of prostaglandin synthesis abolish the $\mathrm{PGI}_{2}$-induced increase in tension in vessels obtained from pancreatectomised dogs. They had attributed this finding to the inhibition of synthesis of a thromboxane $A_{2}$-like substance in arteries from diabetic animals. However, since the production of thromboxane $\mathrm{A}_{2}$ involves an initial pathway in common with $\mathrm{PGI}_{2}$, we would expect that postpancreatectomy lipolysis would exert an inhibitory effect on thromboxane $\mathrm{A}_{2}$ synthesis.

The current status of $\mathrm{PGI}_{2}$ production, and indeed that of other vasoactive prostaglandins in diabetes, remains unclear. One possible explanation of the conflicting reports is that diabetes involves a multiplicity of continually changing plasma metabolic profiles. Each variable making up this profile may influence $\mathrm{PGI}_{2}$ synthesis in a differ- ent fashion. For example, in our experiments in vitro, clinically unacceptable plasma glucose concentrations $(15-30 \mathrm{mmol} / \mathrm{l})$ were stimulatory, whereas high concentrations of ketone bodies had no effect on $\mathrm{PGI}_{2}$ synthesis [8]. Non-esterified fatty acids, as mentioned above, were markedly inhibitory.

Clearly, the relationship of diabetes mellitus with prostaglandin metabolism and vascular abnormalities requires further investigation.

Yours sincerely,

D.P. Mikhailidis, J.Y.Jeremy and P.Dandona

\section{References}

1. Sterin-Borda L, Borda ES, Gimeno MF, Lazzari MA, del Castillo E, Gimeno AL (1982) Contractile activity and prostacyclin generation in isolated coronary arteries from diabetic dogs. Diabetologia 22: 56-59

2. Hamilton G, Rosza I, Hutton R, Chow FPR, Dandona P, Hobbs KEF (1981) Portal vein prostacyclin activity in experimental portal hypertension in rats. Clin Sci 60: 327-329

3. Dandona P, James IM, Newbury PA, Woollard ML, Beckett AG (1978) Cerebral blood flow in diabetes mellitus: evidence of abnormal cerebrovascular reactivity. Br Med J 2: 325-326

4. Dandona P, James IM, Woolard ML, Newbury P, Beckett AG (1979) Instability of cerebral blood flow in insulin-dependent diabetics. Lancet 2: 1203-1206

5. Ewald U, Tuvemot T, Rooth G (1981) Early reduction of vascular reactivity in diabetic children detected by transcutaneous oxygen electrode. Lancet 1: 1287-1288

6. Dandona P, James IM, Beckett AG (1980) Vascular reactivity in diabetes. Lancet 2: 694

7. Gcorgiadis E, Dandona P, Hughes R, Morris R, Woolard ML, Beckett AG, James IM (1981) Cerebral blood flow in patients with diabetic feet. Diabetologia 21: 274 (Abstract)

8. Jeremy JY, Mikhailidis DP, Dandona P (1982) Simulating the diabetic environment modifies prostacyclin synthesis in vitro in the rat. Diabetologia 22: 388 (Abstract)

9. Mikhailidis DP, Mikhailidis AM, Dandona P (1982) The effect of human plasma proteins on the stabilisation of the platelet antiaggregatory activity of prostacyclin. Ann Clin Biochem (in press)

10. Mikhailidis DP, Mikhailidis AM, Dandona P (1981) Plasma nonesterified fatty acid levels and atherogenesis in diabetes mellitus. Diabetologia 21: 499-500

11. Sterin-Borda L, Gimeno M, Borda E, del Castillo E, Gimeno AL (1981) Prostacyclin ( $\mathrm{PGI}_{2}$ ) and U-46619 stimulate coronary arteries from diabetic dogs and their action is influenced by inhibitors of prostaglandin biosynthesis. Prostaglandins 22: 267-278

\section{Dr. P.Dandona}

Metabolic Unit

Department of Chemical Pathology

Royal Free Hospital

Pond Street

London NW3 2QG

UK

Responsible for the text: Prof. A. G. Cudworth, Department of Diabetes, Medical Unit, King George V Building (5th Floor), St. Bartholomew's Hospital, London EC1A 7BE, England

Responsible for advertisements: E. Lückermann, B. Schultz, Kurfürstendamm 237, D-1000 Berlin 15. Springer-Verlag Berlin Heidelberg New York Printed in Germany by aprinta, Wemding

Copyright (c) Springer-Verlag GmbH \& Co. KG, Berlin Heidelberg 1982 